\title{
Calcium-Independent Activation of the Secretory Apparatus by Ruthenium Red in Hippocampal Neurons: A New Tool to Assess Modulation of Presynaptic Function
}

\author{
Louis-Eric Trudeau, Robert T. Doyle, Dennis G. Emery, and Philip G. Haydon \\ Laboratory of Cellular Signaling, Department of Zoology and Genetics, lowa State University, Ames, lowa 50011
}

The functional plasticity of the nervous system may result in part from the direct modulation of the effectiveness of the release machinery of synaptic terminals. To date, direct modulation of secretion in neurons has proven difficult to study because of the lack of a suitable tool to probe the release machinery independently of calcium influx. We report that the polyvalent cation ruthenium red $(\mathrm{RR})$ directly evokes rapid and reversible calcium-independent quantal secretion in hippocampal neurons by binding to external sites on the presynaptic

A characteristic property of the nervous system is its plasticity, or capacity for reorganization, as a function of past experience or after injury. An important site of plasticity in the nervous system is found at chemical synapses. The effectiveness of synaptic transmission can be modified for short or long periods of time through various possible mechanisms. One of these is a change in the amount of neurotransmitter released at presynaptic terminals after action potential-dependent calcium influx. This change may be accomplished in a number of ways. First, there may be a modification in the shape of the action potential. For example, a decrease in potassium conductance could allow broadening of the action potential and a prolonged depolarization of the terminals (Klein, 1994). A prolonged opening of calcium channels and influx of this ion into the terminal would result in an increase in neurotransmitter release. A change in transmitter release may also result more directly from a modulation of the calcium channels (Scholz and Miller, 1991). A third possibility is a direct change in the effectiveness of the release machinery of nerve terminals, i.e., the steps that are downstream from calcium influx and culminate in quantal release of neurotransmitter (Man-SonHing et al., 1989). This third possibility has proven to be more difficult to address but may be of great importance. Indirect evidence has been presented to suggest that this type of plasticity may be involved in the upregulation of excitatory synaptic transmission that characterizes long-term potentiation, a candidate mechanism for the establishment of long-term memory (Malgaroli and Tsien, 1992; Malgaroli et al., 1995).

A major limitation in the assessment of a direct modulation of the release machinery in neurons has been the lack of a suitable

\footnotetext{
Received July 18, 1995; revised Sept. 6, 1995; accepted Sept. 8, 1995.

This work was funded in part by NIH Grants NS233450 and NS26650 to P.G.H., by the McKnight Foundation, and by a Long-Term Fellowship from the Human Frontier Science Program to L.-E.T. We thank Drs. M. McCloskey and S. Shen as wcll as T. A. Basarsky for fruitful discussions and help in rcvicwing this manuscript.

Correspondence should be addressed to Dr. L.-E. Trudeau, Laboratory of Cellular Signaling, Department of Zoology and Genetics, Iowa State University, 339 Science II building, Ames, IA 50011.

Copyright $\odot 1995$ Society for Neuroscience $0270-6474 / 95 / 160046-09 \$ 05.00 / 0$
}

terminal membrane. This binding can be displaced by heparin and is not associated with ultrastructural damage to the synaptic terminals. The use of RR-evoked release as a tool has allowed us to detect a direct modulation of the secretory apparatus after activation of $A_{1}$ adenosine receptors on hippocampal neurons.

Key words: miniature synaptic currents; calcium; ruthenium red; secretion; hippocampus; synapse

tool to induce neurotransmitter release independently of calcium influx through calcium channels. Using invertebrate neurons, we and others have shown previously that one method that may be effective is to provide calcium to the release machinery directly by flash photolysis of caged calcium (Zucker and Haydon, 1988; Man-Son-Hing et al., 1989; Delaney and Zucker, 1990; Mulkey and Zucker, 1993). However, the technical difficulties associated with this method limit its routine use, especially in mammalian neurons. Other tools that have previously been found to be useful in probing the release machinery of neurons include $\alpha$-latrotoxin as well as hyperosmotic challenges. The usefulness of the first approach is limited by its nonreversibility as well as by its mixed calcium-dependent and calcium-independent modes of action (Rosenthal et al., 1991). The use of hyperosmotic saline to induce neurosecretion in the context of investigations of modulation of release also is limited for the moment, owing to uncertainties about the calcium dependence of its mode of action (Landò et al., 1986). For example, it has proven difficult to use calcium-sensitive dyes to monitor intracellular calcium dynamics because of potential problems caused by changes in cell volume and intracellular ionic concentrations caused by this stimulus (Delaney et al., 1991). Yet additional agents that have been used to induce increases in the frequency of spontaneous release of neurotransmitter quanta (minis) include ethanol, chlorpromazine, and ouabain. The action of ethanol seems to be independent of calcium (Brosius et al., 1992), but its effects on spontaneous release are obtained only at high concentrations, which also cause significant postsynaptic alterations and change miniamplitude (Gage, 1965; Quastel et al., 1971). The action of both chlorpromazine and ouabain on minifrequency apparently is independent of external calcium, but has not been shown to be independent of internal calcium (Argov and Yaari, 1975; Baker and Crawford, 1975). These two agents also accelerate minifrequency only after a prolonged delay and, in the case of ouabain, can be associated with ultrastructural damage to synaptic terminals (Haimann et al., 1985). Finally, previous work has shown that minifrequency could be changed after the application of neuromodulators, thereby suggesting a direct presynap- 
tic modulation (Scanziani et al., 1992; Scholz and Miller, 1992). This later type of analysis certainly is useful but is not necessarily a very sensitive assay of the state of the secretory apparatus. Spontaneous minifrcquency also could bc influenced by changes in the resting levels of calcium in synaptic terminals. Considering these limitations, we sought to develop a new tool to directly probe the release apparatus of neurons.

Within this context we found it intriguing that polyvalent cations such as lanthanum and ruthenium red (RR) reliably increase the rate of miniature end-plate potentials and synaptic currents (Heuser and Miledi, 1971; Alnaes and Rahamimoff, 1975; Raastad et al., 1990; Grubb et al., 1991). The mechanism of action of this induction of release has not been characterized in detail, although it generally has been thought to involve changes in intraterminal calcium levels. Morphological observations of lanthanum-treated neuromuscular junctions have shown previously that prolonged treatments could induce depletion of clear vesicles, whereas tetanus-toxin pretreated junctions exposed to lanthanum for short durations displayed an enhanced number of vesicles in close apposition to the presynaptic membrane (Mellanby et al., 1988). This suggests that such treatments may facilitate interactions between vesicles and the presynaptic membrane. Lanthanum also has been reported to promote catecholamine release from chromaffin cells (Powis et al., 1994). Here we have investigated in more detail the mode of action of RR at synapses formed between hippocampal neurons in primary culture and find that it is an extremely effective tool to induce quantal neurotransmitter release. We show that its action is reversible and calciumindependent and provide evidence suggesting that it acts by binding to an external site on the presynaptic plasma membrane. Additionally, we use the $A_{1}$ adenosine receptor agonist cyclopentyladenosine (CPA) to illustrate the use of RR as an effective tool in detecting a direct modulation of the secretory apparatus. We find that RR-evoked neurotransmitter release is a highly sensitive assay of the state of the secretory machinery of nerve terminals.

\section{MATERIALS AND METHODS}

Cell culture. Primary mixed cultures of hippocampal neurons and astrocytes were prepared as described in Basarsky et al. (1994). Briefly, hippocampi were dissected from rats 1-3 d after birth. Neurons were dissociated mechanically in $\mathrm{Mg}^{2+}$-free Earle's balanced salt solution (Gibco, Grand Island, NY) after a 60 -min papain digestion. Cells were plated onto poly-L-lysine-coated glass coverslips and maintained in culture media containing $10 \%$ fetal bovine serum (Sigma, St. Louis, MO). The mitotic inhibitor arabinosylcytosine $(5 \mu \mathrm{M})$ was added to the cultures 3-4 d after plating. Neurons were used after 10-20 d in culture.

Electrophysiology. Hippocampal neurons plated on glass coverslips were visualized by phase-contrast microscopy on a Nikon Diaphot inverted microscope. Whole-cell patch clamp recordings were obtained from the neurons with an Axopatch-1D amplifier (Axon Instruments, Foster City, CA). Patch pipettes were pulled in two stages from a PP-83 puller (Narashige, Tokyo, Japan); their resistance was between 4 and 8 $\mathrm{M} \Omega$ when filled with the normal recording solution. The normal internal recording solution consisted of CsGluconate $117.5 \mathrm{mM}, \mathrm{NaCl} 10 \mathrm{~mm}$, $\mathrm{MgCl}_{2} 4 \mathrm{mM}$, EGTA $5 \mathrm{~mm}$, Mg-ATP $2 \mathrm{~mm}$, Tris-GTP $0.2 \mathrm{~mm}$, and HEPES $15 \mathrm{~mm}$. The normal external saline was $\mathrm{NaCl} 140 \mathrm{mM}, \mathrm{MgCl}_{2} 2$ $\mathrm{mM}, \mathrm{CaCl}_{2} 2 \mathrm{~mm}$, KCl $5 \mathrm{~mm}$, HEPES $10 \mathrm{~mm}$, sucrose $6 \mathrm{~mm}$, and glucose $10 \mathrm{~mm}, \mathrm{pH}$ 7.35. The saline used for recording miniature excitatory synaptic currents also contained $1 \mu \mathrm{M}$ TTX to block sodium channels and $10 \mu \mathrm{M}$ SR-95531 or $100 \mu \mathrm{M}$ picrotoxin to block $\mathrm{GABA}_{\mathrm{A}}$ receptors. To isolate calcium currents, barium was used as the charge carrier, and the external saline was $\mathrm{BaCl}_{2} 10 \mathrm{~mm}$, TEA-Cl $160 \mathrm{~mm}$, and HEPES $10 \mathrm{~mm}$, pH 7.4 (adjusted with TEA-OH). For these expcriments, the internal recording solution was TEA-Cl $117 \mathrm{~mm}, \mathrm{MgCl}_{2} 4.5 \mathrm{~mm}$, EGTA $9 \mathrm{~mm}$, Mg-ATP $4 \mathrm{~mm}$, Tris-GTP $0.3 \mathrm{~mm}$, and creatine phosphate (Tris salt) 14 $\mathrm{mM}, \mathrm{pH} 7.4$ (adjusted with TEA-OH). All recordings were performed at room temperature $\left(20-22^{\circ} \mathrm{C}\right)$. Currents were high-pass filtered at $2 \mathrm{kHz}$ and digitized at 5 or $10 \mathrm{kHz}$. The data were acquired using pClamp softwarc from Axon Instruments (v. 6.0). Miniaturc synaptic currents were analyzed further with the ACSPLOUF minianalysis software (obtained from Dr. Pierre Vincent, University of California at San Diego). Group data presented in the text are expressed as mean \pm SEM, unless stated otherwise.

Calcium imaging. Methods for ratiometric determination of intracellular calcium were as described in Basarsky et al. (1994). Briefly, cultured neurons were loaded at $37^{\circ} \mathrm{C}$ with $2 \mu \mathrm{M}$ Fura- $2 \mathrm{AM}$ (Molecular Probes, Eugene, OR) for $45 \mathrm{~min}$ in the presence of $0.025 \%$ Pluronic F-127. The culture was then washed, and de-esterification was allowed to proceed for $45 \mathrm{~min}$ at $37^{\circ} \mathrm{C}$ before starting experiments. Images were acquired using a CH-250-cooled CCD camera (Photometrics, Tucson, $\mathrm{AZ}$ ) and Metafluor software (Universal Imaging, West Chester, PA).

Electron microscopy. Cultures were fixed for $90 \mathrm{~min}$ in a mixture of $1 \%$ $p$-formaldelyde and $2 \%$ glutaraldehyde and $0.25 \%$ tannic acid in $0.1 \mathrm{M}$ cacodylate buffer and postfixed for $15 \mathrm{~min}$ in $0.5 \%$ osmium tetroxide plus $0.8 \%$ potassium ferricyanide in the same buffer. After en-block staining with magnesium-uranyl acetate ( $1 \%$, aqueous, $2 \mathrm{hr}$ ), cultures were embedded in Epon resin. Thin sections were stained with Reynolds lead citrate before viewing.

Drugs. Tetrodotoxin, RR, picrotoxin, heparin (sodium salt, MW $\approx 6000$ ), Mg-ATP, and Tris-GTP were from Sigma (St. Louis, MO). $N^{6}$-cyclopentyladenosine, CNQX, and SR-95531 were from Research Biochemicals (Natick, MA).

\section{RESULTS}

\section{Rapid and reversible induction of secretion}

We first determined whether the action of RR on secretion was a general phenomenon that is not limited to the neuromuscular junction. This was investigated at synaptic connections established between postnatal rat hippocampal neurons in primary culture. Except where indicated, $1 \mu \mathrm{M}$ TTX and $10 \mu \mathrm{M}$ SR-95531 (GABA receptor antagonist) were added to the external saline to prevent action potential firing and to isolate spontaneous miniature excitatory postsynaptic currents (mEPSCs). At a holding potential of $-70 \mathrm{mV}$, mEPSCs were easily resolved and appeared as rapid inward currents. mEPSCs were recorded for durations of $15 \mathrm{sec}$ before and in the presence of RR. Focal application of RR from a pressure ejection pipette ( $30 \mathrm{sec}$ puff) at $30 \mu \mathrm{M}$ in the immediate vicinity of the neuron that was voltage-clamped evoked a brisk and clearly detectable increase in the frequency of occurrence of mEPSCs in all cells tested $(n=31$; Fig. $1 A)$. On average, an 11.1 \pm 1.5 -fold increase in mEPSC frequency was obtained $(p<0.001$; paired $t$ test). This was not associated with any increase in the holding current. A slow outward current was actually observed in some cells. In initial experiments carried out in the absence of $\mathrm{GABA}_{\mathrm{A}}$ receptor antagonists, we also found that the action of $\mathrm{RR}$ on secretion was not restricted to glutamatergic synaptic terminals. RR was equally effective at increasing the frequency of miniature inhibitory postsynaptic currents (results not shown).

The kinetics of RR action are rapid (Fig. $1 B$ ); upon application from a puffer pipette, the effect develops within the first second and reaches a steady-state level within $5 \sec (n=9)$. Figure $1 C$ also shows that the elevation in mEPSC frequency by RR is both reversible and reproducible if the two puffs are separated by a 5 min wash period $(n=6)$. A two-way ANOVA confirmed that the overall effect of RR was significant $(\mathrm{F}(1,23)=9.16, p<0.01)$ and that there was no significant difference between the magnitude of RR-evoked secretion during the two applications. A dose-response curve of the effect of RR on the occurrence mEPSCs was established (Fig. 2A). An increase in mEPSC frequency could be detected with concentrations as low as $1 \mu \mathrm{M}$. The $\mathrm{EC}_{50}$ was found to be $\sim 5 \mu \mathrm{M}$.

The effect of RR on synapses is apparently strictly presynaptic inasmuch as the cumulative probability distribution of $\mathrm{mEPSC}$ 
A
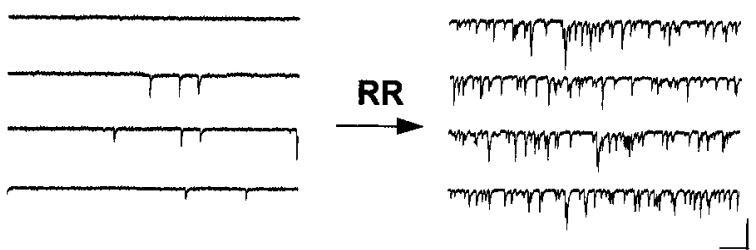

B

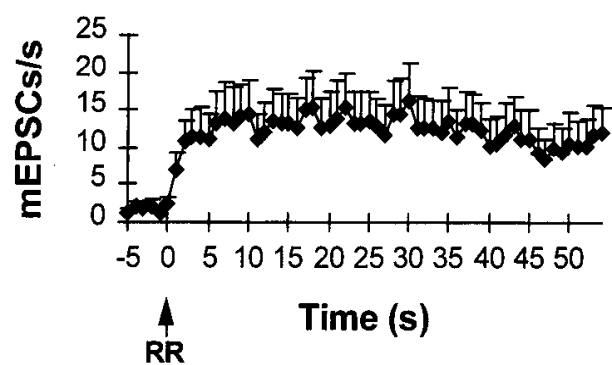

C

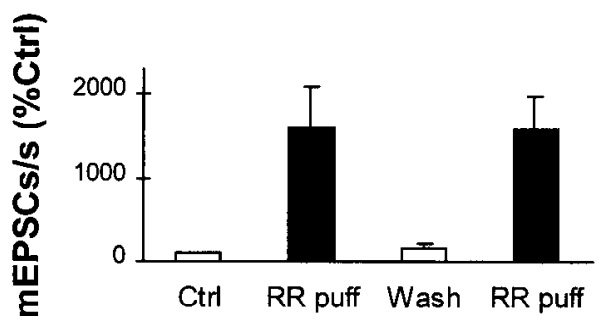

Figure 1. Rapid and reversible action of RR on secretion. $A$, mEPSCs recorded in a voltage-clamped cultured hippocampal neuron at a holding potential of $-70 \mathrm{mV}$ before (left) and after (right) puff application of 30 $\mu \mathrm{M}$ RR. Calibration: $90 \mathrm{pA}, 150 \mathrm{msec} . B$, Time course of the increase in mEPSC frequency after puff application of RR (arrow). mEPSCs were recorded and summed in $1 \mathrm{sec}$ bins for a total of $60 \mathrm{sec}$. Each point represents the mean \pm SEM for each bin $(n=9)$. $C$, Summary of six experiments in which RR was puff-applied twice to the same cell. mEPSCs were recorded for $15 \mathrm{sec}$ before and during RR. The wash period was 5 min. Data were normalized to the number of mEPSCs recorded in the initial control episode of each experiment.

amplitudes is not detectably modified in the presence of RR (Fig. $2 B)(n=8 ; \mathrm{F}(1,1263)=0.35, p=0.55$ [for control vs $\mathrm{RR}$ main effect]; two-way ANOVA). Overall, the amplitude of mEPSCs in the presence of RR was $99.6 \pm 9.0 \%$ of that in normal saline (Fig. $2 B$, inset). Additionally, the CNQX-sensitive currents produced by puff application of L-glutamate on the neurons are unaffected by RR (Fig. 2C) $(n=7 ; p=0.15$; paired $t$ test).

\section{Calcium-independent mode of action}

The calcium dependence of the action of RR was first investigated by verifying whether removal of external calcium could prevent the increase in mEPSC frequency produced by $\mathrm{RR}$. The external saline contained no added calcium and $1 \mathrm{~mm}$ EGTA. In these and the following experiments, the number of mEPSCs was measured for a duration of $15 \mathrm{sec}$ before and after application of RR. The difference score was held to represent RR-evoked release. The RR-evoked release was measured first in normal saline, then again after 3-5 min in the modified saline. Figure $3 A$ illustrates that in the absence of external calcium, the efficacy of RR was in no way decreased. In five out of seven experiments, RR-evoked release was actually found to be increased. On average, the $\mathrm{RR}$-evoked release measured in $\mathrm{Ca}^{2+}$-free saline was $160.8 \pm$ $21.3 \%$ of that measured in normal saline (Fig. $3 B$ ). Overall however, this increase was not statistically significant $(n=7 ; p=0.18$;
A

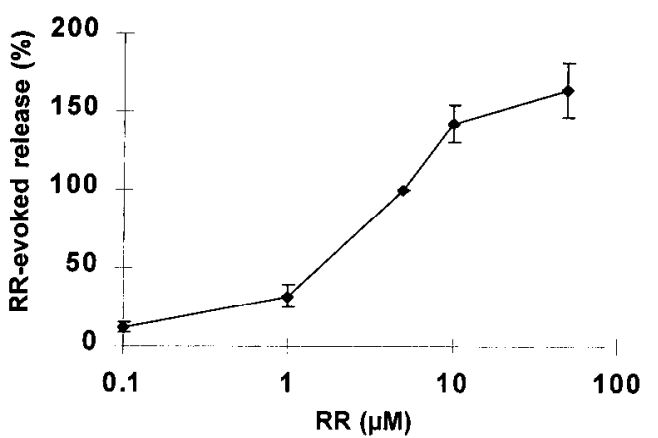

B

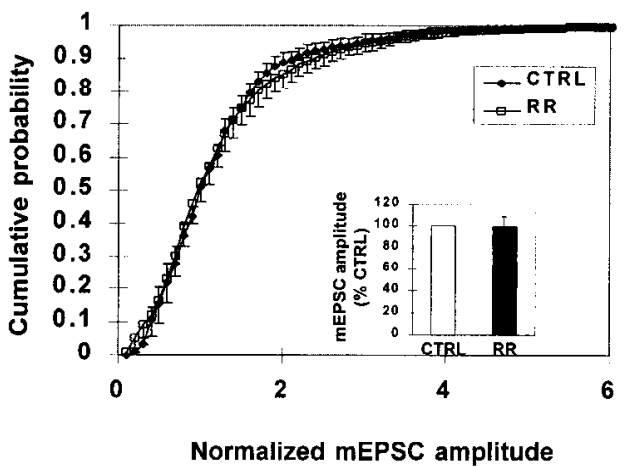

C

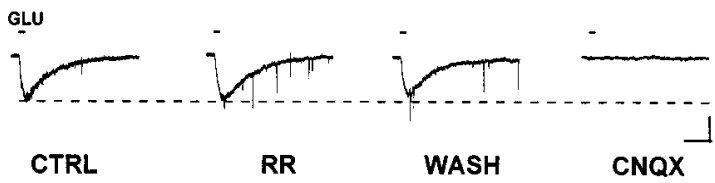

Figure 2. High affinity presynaptic action of RR. A, Dose-response curve of the effect of RR on mEPSCs in cultured hippocampal neurons. mEPSCs were recorded at a holding potential of $-70 \mathrm{mV}$ in the presence of increasing concentrations of RR applied by perfusion. The number of mEPSCs recorded in each $15 \mathrm{sec}$ episode was normalized to the response obtained at $5 \mu \mathrm{M}$ for each experiment. Each point represents the mean \pm SEM for four to eight experiments. $B$, Cumulative probability plot of the amplitude of mEPSCs recorded before (CTRL) and in the presence of puff-applied RR $(30 \mu \mathrm{M})$. The mEPSCs (recorded in 15 sec episodes) were normalized to the modal mEPSC amplitude of the control episode of each experiment. The normalized $\mathrm{mEPSC}$ amplitudes were then ranked and divided in 0.1 unit bins for the subsequent establishment of a cumulative probability plot. The probability determined for each bin was averaged across eight experiments. The points represent the mean \pm SEM for each bin. 'The inset illustrates the effect of $\mathrm{KK}$ on the average mEPSC amplitude (normalized to the average amplitude of mEPSCs in the control episode of each experiment). $C$, Effect of RR $(30 \mu \mathrm{M})$ on currents induced by puff-applied glutamate $(500 \mu \mathrm{M}$ for $15 \mathrm{msec})$ in a neuron voltageclamped at $-70 \mathrm{mV}$. The current was completely blocked by $20 \mu \mathrm{M}$ CNQX (right). Calibration: $40 \mathrm{pA}, 400 \mathrm{msec}$

paired $t$ test). The tendency for the effect of RR to be increased in $\mathrm{Ca}^{2+}$-free saline suggested that there might be a competition for binding sites between RR and the calcium ions that are normally present in the saline. This was evaluated by increasing external calcium from $2 \mathrm{~mm}$ to $10 \mathrm{~mm}$. Under these conditions, the effectiveness of RR was clearly diminished. On average, RRevoked release in $10 \mathrm{mM} \mathrm{Ca}^{2+}$-saline was $41.5 \pm 10.6 \%$ of that in normal saline (Fig. $3 B)(n=5 ; p<0.05$; paired $t$ test).

The broad-spectrum calcium channel blocker cobalt chloride $\left(\mathrm{CuCl}_{2}\right)$ was used to test more directly whether calcium influx through voltage-dependent calcium channels could play a role in 
A
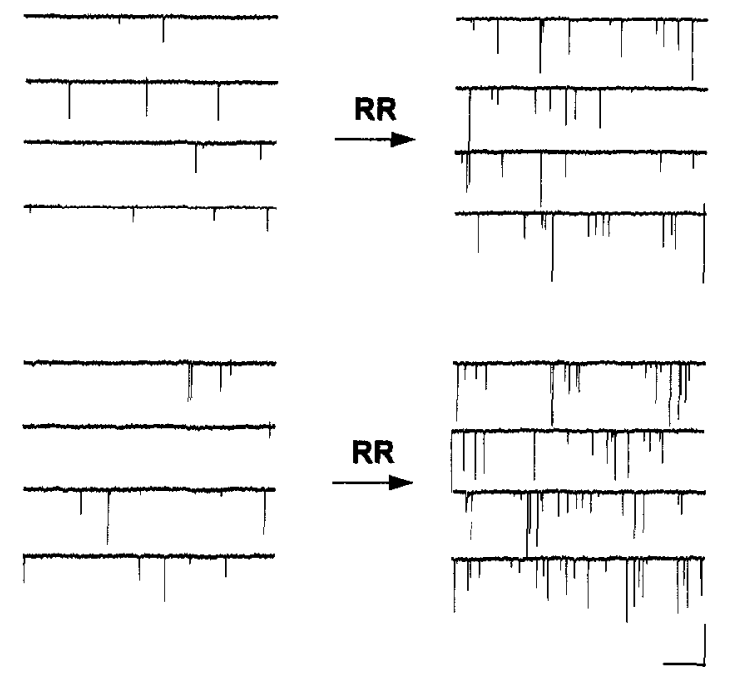

B

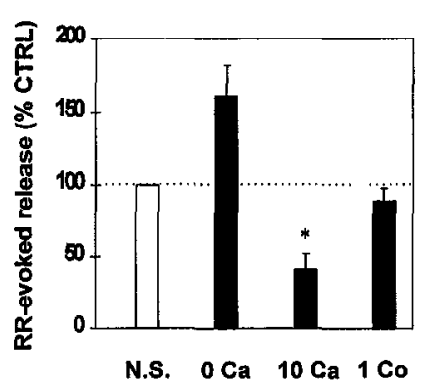

C

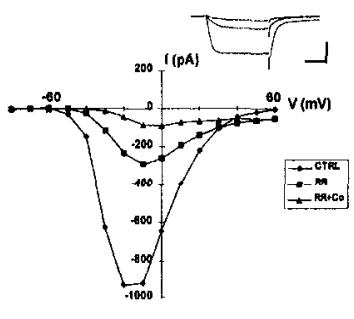

A

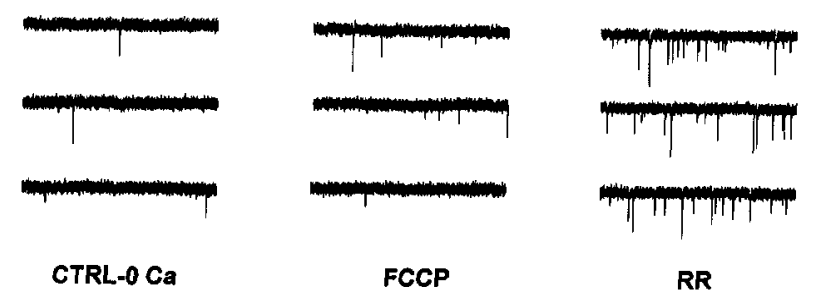

B

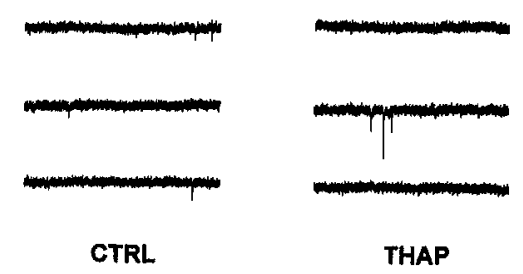

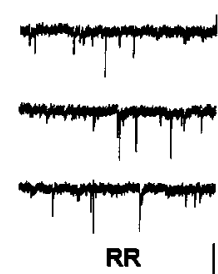

Figure 3. RR-induced secretion is independent of external calcium. $A$, mEPSCs recorded in a neuron at a holding potential of $-70 \mathrm{mV}$. The effect of puff-applied RR $(30 \mu \mathrm{M})$ was investigated in the same cells first in normal saline (N.S.) and then after the perfusion of $\mathrm{Ca}^{2+}$-free saline $(0 \mathrm{Ca})$ for $3-5 \mathrm{~min}$. Note that the effect of RR is actually slightly greater in that cell in the absence of external $\mathrm{Ca}^{2+}$. Calibration: $75 \mathrm{pA}, 475 \mathrm{msec}$. $B$, Summary of experiments testing the role of external $\mathrm{Ca}^{2+}$ in the effects of RR on secretion. RK-evoked release was computed as the difference between the number of $\mathrm{mEPSCs}$ recorded in the $15 \mathrm{sec}$ episode before and immediately after puff application of RR. RR-evoked release was measured twice for each neuron: first in a control period in normal saline (N.S.) and then in either $0 \mathrm{Ca}^{2+}$ saline $(0 \mathrm{Ca})(n=7), 10 \mathrm{mM} \mathrm{Ca}^{2+}$ saline $(10 \mathrm{Ca})(n=5)$ or in saline containing $1 \mathrm{mM} \mathrm{CoCl}(1 \mathrm{Co})(n=5)$. The effect of RR was significantly diminished in the presence of $10 \mathrm{mM} \mathrm{Ca}^{2+}$. Each column represents the mean \pm SEM. ${ }^{*} p<0.05$. $C$, The graph represents a current-voltage relationship of the $\mathrm{Ca}^{2+}$ current recorded in a neuron in a control period, and after the successive perfusion of $30 \mu \mathrm{M}$ $\mathrm{RR}$ and $1 \mathrm{mM} \mathrm{CoCl}_{2}$. The holding potential was $-80 \mathrm{mV}$. Barium was the charge carrier. The inset shows leak-subtracted current traces obtained by stepping from -80 to $-10 \mathrm{mV}$ for $50 \mathrm{msec}$. The lower trace is the control, the middle is in the presence of $\mathrm{RR}$, and the top is after perfusion of $\mathrm{CoCl}_{2}$. Calibration: $520 \mathrm{pA}, 15$ msec.

the effects of RR. We found that the ability of RR to evoke secretion was unhampered (Fig. 3B) at a concentration of $\mathrm{CoCl}_{2}$ $(1 \mathrm{mM}$ ), which potently blocks calcium currents in these cells (see Fig. $3 C$ ). On average, $\mathrm{RR}$-evoked release in $\mathrm{CoCl}_{2}$-saline was 88.7 $\pm 9.0 \%$ of that in normal saline. The difference was not statistically significant ( $p=0.19$; paired $t$ test). These later results might not be surprising in the light of previous reports suggesting that $\mathrm{RR}$ itself is an effective blocker of voltage-dependent calcium channels (Gomis et al., 1994). This is illustrated in Figure 3C, which presents a current-voltage relationship for the calcium current $\left(\mathrm{I}_{\mathrm{Ca}}\right)$ recorded in a neuron at a holding potential of -80 $\mathrm{mV}$, using barium as the charge carrier. It shows that at a concentration of $30 \mu \mathrm{M}, \mathrm{RR}$ was effective at blocking calcium currents

in these neurons. A block of $63.0 \pm 3.3 \%$ of the peak $\mathrm{I}_{\mathrm{Ca}}$ was obtained ( $n=6 ; p<0.05$; paired $t$ test). Most of the residual current could be blocked by $1 \mathrm{mM} \mathrm{CoCl}_{2}$ (Fig. $3 \mathrm{C}$ ). Together, $\mathrm{KR}$ and $\mathrm{CoCl}_{2}$ blocked $87.8 \pm 4.9 \%$ of the initial $\mathrm{I}_{\mathrm{Ca}}(n=5 ; p<0.05$; paired $t$ test). These results suggest that it is unlikely that RR acts by promoting influx of calcium through voltage-gated calcium channels.

The possibility of an action of $R R$ on intracellular calcium stores also was investigated. It is known that in vitro, $\mathrm{RR}$ blocks the $\mathrm{Ca}^{2+}$ uniporter of mitochondria and can induce the release of calcium from mitochondria under some conditions, although evidence for any such action on intact cells is scarce (Moore, 1971; Broekemeier et al., 1994). The role of mitochondrial stores was probed by the use of FCCP, a proton ionophore that dissipates the mitochondrial proton gradient and allows the release of calcium from loaded mitochondria. We reasoned that if $R R$ induced release of calcium from these stores, then pretreatment with FCCP should decrease RR-evoked release. Because FCCP also is able to depolarize cellular membranes with the associated problem of opening calcium channels (White and Reynolds, 1995), these experiments were performed in $\mathrm{Ca}^{2+}$-frec salinc. The effect of RR was tested 3-5 min after the application of FCCP. In six of six experiments, FCCP $(1 \mu \mathrm{M})$ induced a small increase in baseline $\mathrm{mEPSC}$ frequency (2.6 \pm 0.3 -fold change). However, the subsequent application of RR induced a clear increase in mEPSC frequency in every neuron tested (Fig. 4A). In four of these experiments, the effect of RR was evaluated both before and after FCCP. We found that RR-evoked release after FCCP was $161.2 \pm$ $13.7 \%$ of that in normal saline. The increase was not statistically significant ( $p=0.07$; paired $t$ test).

The involvement of other calcium stores such as those associ- 
ated with the endoplasmic reticulum was investigated by using the $\mathrm{Ca}^{2+}$-ATPase blocker thapsigargin, an agent that is known to deplete such stores in many cell types. The effect of RR was tested 3-5 min after the application of thapsigargin. We found that by itself, thapsigargin $(1 \mu \mathrm{M})$ was unable to reliably increase the occurrence of mEPSCs in these neurons. Only in one out of eight cells tested was a clear increase detected. On average, the basal minifrequency in the seven other cells was $143.3 \pm 40.0 \%$ of control. The difference was not statistically significant $(p=0.41$; paired $t$ test). In all six cells in which RR was tested after thapsigargin treatment, a clear increase in mEPSC frequency was obtained (Fig. 4B). In four of these experiments, the effect of RR was tested both hefore and after application of thapsigargin. We found that RR-evoked release after thapsigargin was $122.0 \pm$ $8.1 \%$ of that in normal saline. The difference was not statistically significant ( $p=0.23$; paired $t$ test). These results, using thapsigargin and FCCP, suggest that the induction of secretion by RR does not require any release of calcium from internal stores.

We tested more directly the possibility that RR could induce an elevation of free calcium in the neurons by using the calciumsensitive probe Fura-2 for ratiometric determination of calcium levels. In all experiments with RR, no significant increase in intracellular calcium was detectable, either in cell bodies or in neurites. To rule out a detection threshold problem, we verified whether we could detect a change in intracellular calcium when neurons were depolarized with saline containing $15 \mathrm{mM} \mathrm{KCl}$. In preliminary experiments we determined that this concentration of $\mathrm{K}^{+}$could depolarize the neurons sufficiently to induce an elevation of mEPSC frequency that was roughly of the same order of magnitude as that produced by RR (Fig. $5 A, B$ ). On average, the increase in mEPSC frequency produced by the $15 \mathrm{~mm} \mathrm{~K}^{+}$saline was $7.3 \pm 1.4$-fold ( $p<0.01$; paired $t$ test). In comparison, RR produced an $11.1 \pm 1.5$-fold increase, as mentioned earlier. We found that the $15 \mathrm{mM} \mathrm{K}^{+}$saline produced a clearly detectable elevation of free calcium in the neurites and cell bodies of all cells tested (Fig. 5B). On average, free calcium increased by $54 \pm 8 \mathrm{~nm}$ after application of the $15 \mathrm{~mm} \mathrm{~K}^{+}$saline $(n=38$ fields in 5 coverslips), whereas in the same cells, the change produced by 30 $\mu \mathrm{M}$ RR was $-1 \pm 1 \mathrm{nM}$. Together with the observation that the action of RR persists in the absence of external calcium and after perturbation of intracellular calcium stores, these results are compatible with the idea that the induction of secretion by RR is calcium-independent.

\section{External site of action}

Although puff-applied RR reversibly increased mEPSC frequency, we noticed that the effect was difficult to completely reverse after slow application of RR through the perfusion line. One interpretation of this observation is that some of the RR remained bound to the presynaptic membrane through relatively tight interactions that were difficult to remove by washing with saline. Another possibility is that some of the RR remained trapped inside the nerve terminals. We reasoned that if the first model was correct, it should be possible to compete with these putative RR binding sites by using a polyanionic molecule such as heparin. Previous work has shown that heparin can interact strongly with RR in vitro (Luft, 1971; Moore, 1971). In these experiments RR $(30 \mu \mathrm{M})$ was perfused for $60 \mathrm{sec}$ and then immediately washed out for $2-4 \mathrm{~min}$ with normal saline. The mEPSC frequency remained well above control levels in all cases and was relatively stable (Fig. $6 B, C T R L)$. Heparin $(100 \mu \mathrm{M})$ was then puffed for $30 \mathrm{sec}$ in the immediate vicinity of the neuron that
A

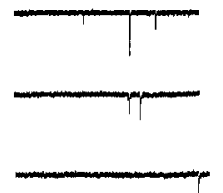

CTRL

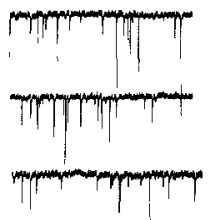

KCL-15 mM

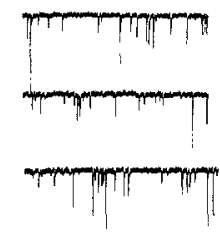

$\mathbf{R} \mathbf{R}$
B

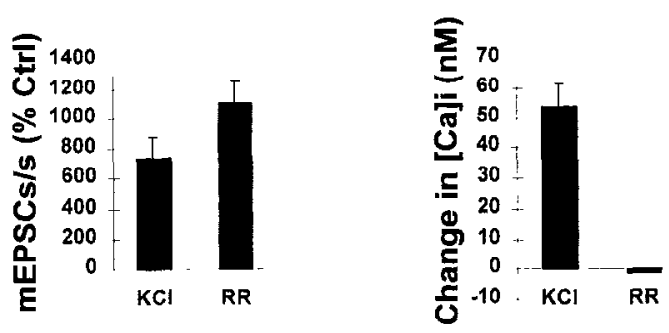

Figure 5. RR induces no detectable change in neuronal calcium levels. $A$, $\mathrm{mEPSCs}$ recorded in a neuron at a holding potential of $-70 \mathrm{mV}$. Perfusion of saline containing $15 \mathrm{~mm} \mathrm{KCl}$ induced a clear increase in $\mathrm{mEPSC}$ frequency (middle). The subsequent puff application of RR $(30 \mu \mathrm{M})$ produced a comparable increase in mEPSC frequency in that cell (right). Calibration: $80 \mathrm{pA}, 800 \mathrm{msec} . B$, Summary of calcium imaging and mEPSC recording experiments. The left histograms represent the change in mEPSC frequency induced by $15 \mathrm{mM} \mathrm{KCl}$ saline or by $\mathrm{RR}$. The right histograms represent the change in free calcium (relative to control) produced by the same treatments in different neurons. Data are presented as mean \pm SEM. Note that although RR produced a larger increase in $\mathrm{mEPSC}$ than did the $15 \mathrm{mM} \mathrm{KCl}$ saline, it failed to induce any detectable increase in free calcium. The $\mathrm{KCl}$ saline induced an average change in calcium of $54 \mathrm{~nm}$.

was patch-clamped. In all experiments $(n=6)$, puff-applied heparin produced an immediate decrease in mEPSC frequency (Fig. $6 A, B)$. Slow application of heparin through the perfusion line also was found to be effective ( $n=10$; results not shown). The presynaptic nature of the effect of heparin is supported by the finding that the reversal of RR action was not accompanied by any notable change in the cumulative probability distribution of mEPSC amplitudes (Fig. 6C) $(F(1,959)=0.51, p=0.47$ (for control vs heparin main effect); two-way ANOVA). Overall, the average amplitude of mEPSCs after application of heparin was $97.2 \pm 9.6 \%$ of that in the control period (Fig. $6 \mathrm{C}$, inset). The size of CNQX-sensitive currents obtained by direct puff application of glutamate also was found to be unaffected by heparin $(99.7 \pm$ $3.0 \%$ of control; $n=8 ; p=0.83$; paired $t$ test) (Fig. $6 D$ ). These results, together with the observation that high external calcium strongly decreases the effects of RR on secretion, are compatible with a model of RR action that involves binding to sites on the extracellular side of the presynaptic membrane.

The finding that RR seems to act through an external site may not be surprising in light of previous observations suggesting that, as is the case for lanthanum, it is impermeant to intact cellular membranes (Tani and Ametani, 1971; Korte and Rosenbluth, 1982; Humbert and Pévet, 1992) and may be used as a histological stain of the cell surface (Luft, 1971; Parsons et al., 1992). We wished to verify whether its binding to the presynaptic membrane could be associated with any detectable perturbations of the synapse at the ultrastructural level. Neurons were exposed to 20 $\mu \mathrm{M}$ RR for $10 \mathrm{~min}$ and then immediately fixed and processed for electron microscopy. We found that RR application did not com- 
A

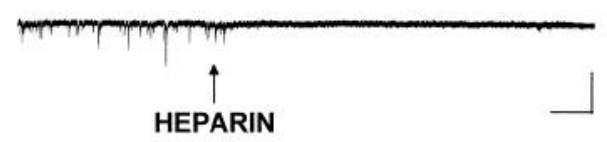

B

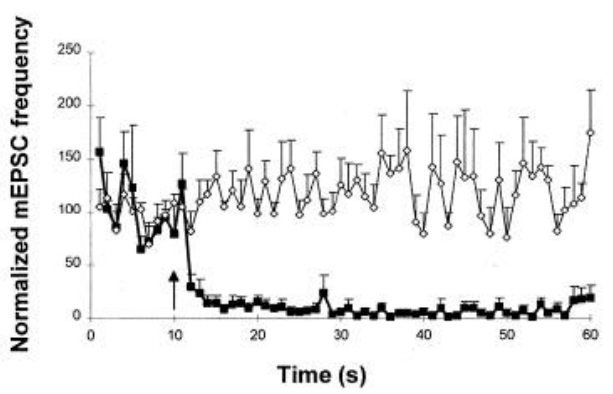

CTRL

HEPARIN

C

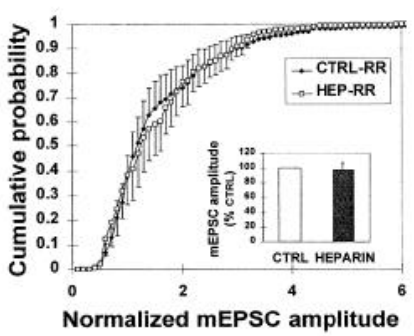

D

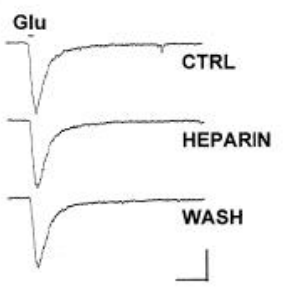

Figure 6. RR acts at an external site. Cultures were perfused for $60 \mathrm{sec}$ with $30 \mu \mathrm{M}$ RR and then washed with saline for 2-4 min. This lead to a sustained increase in mEPSCs that persisted even after washout of RR. The mEPSCs shown in $A$ were recorded after the washout of RR. The persistent effect of RR on mEPSC frequency is rapidly reversed by puff-applied heparin $(100 \mu \mathrm{M})$. Calibration: $50 \mathrm{pA}, 2250 \mathrm{msec}$. $B$, Time course of heparin reversal of RR action. The number of mEPSCs per $1 \mathrm{sec}$ bin was normalized to the modal number of events in the 10 control bins preceding the application of heparin (black squares). The effect of heparin was maximal within $2-3 \mathrm{sec}$. The control plot (white diamonds) illustrates that in the absence of heparin, the effect of RR was maintained. The points represent the mean \pm SEM for each bin $(n=7)$. $C$, Cumulative probability distribution of normalized mEPSC amplitudes before and after heparin. The mEPSCs recorded in the first 10 sec of each experiment were compared with those from the last $50 \mathrm{sec}$ (after the heparin puff). The mEPSCs were normalized to the modal mEPSC amplitude of the control segment of each experiment. The normalized mEPSC amplitudes were then ranked and divided into 0.1 unit bins for the subsequent establishment of a cumulative probability plot. The probability determined for each bin was averaged across seven experiments. The points represent the mean \pm SEM for each 0.1 unit bin. There was no significant difference. The inset illustrates the effect of heparin on the average mEPSC amplitude (normalized to the average amplitude of mEPSCs before the treatment for each experiment). $D$, Currents produced in a voltage-clamped neuron by puff application of glutamate (Glu; $500 \mu \mathrm{M}$ for $15 \mathrm{msec}$ ). Perfusion of 100 $\mu \mathrm{M}$ heparin induced no changes in this response. Calibration: $200 \mathrm{pA}$, 160 msec.

promise the ultrastructural integrity of the synapse. Both pre- and postsynaptic membranes seemed undamaged, and large numbers of electron lucent synaptic vesicles were detectable (Fig. 7).

\section{Direct modulation of the secretory apparatus by CPA}

The ability of RR to induce neurotransmitter release independently of calcium and in a reversible manner should provide a very sensitive tool to probe the release machinery of neurons and to allow detection of a direct modulation of the secretory apparatus. Here we used RR-evoked release to test whether activation of presynaptic $A_{1}$ adenosine receptors could directly modulate the effectiveness of quantal secretion. Previous work has shown that

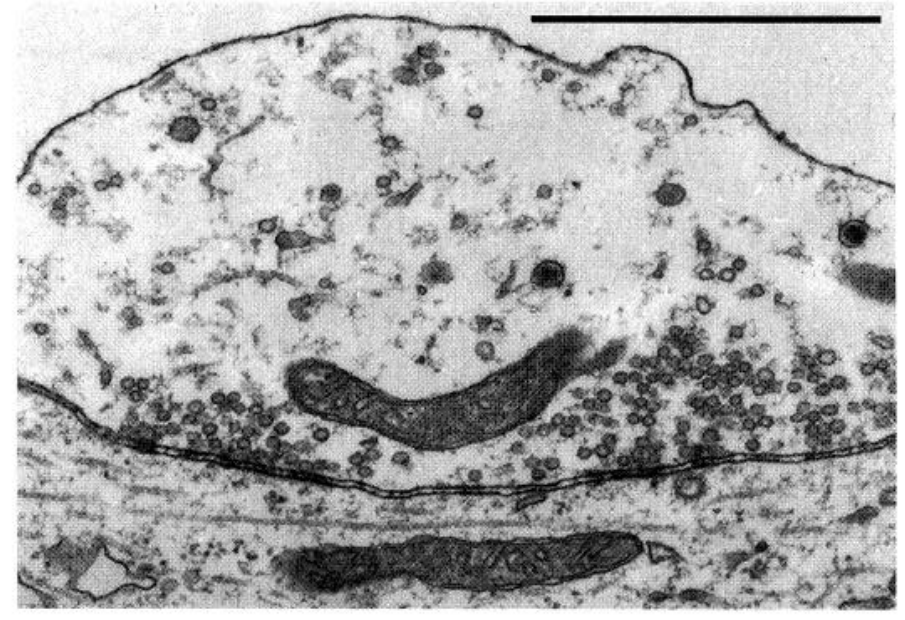

Figure 7. RR does not compromise the ultrastructural integrity of the synapse. Electron micrograph of a section taken from an $11 \mathrm{~d}$ hippocampal culture exposed to RR $(20 \mu \mathrm{M})$ for $10 \mathrm{~min}$ before fixation. The overall appearance of synapses from RR-treated cultures did not differ from that of control cultures (not shown). Calibration: $1 \mu \mathrm{m}$.

activation of these receptors using CPA can very effectively decrease action potential-evoked excitatory synaptic transmission between hippocampal neurons (Scholz and Miller, 1991). Although a decrease in presynaptic calcium current is likely to play some role in the reduced synaptic transmission (Mogul et al., 1993; Umemiya and Berger, 1994; Wu and Saggau, 1994), the observation that basal rates of spontaneous release are also decreased by CPA (Scanziani et al., 1992; Scholz and Miller, 1992) has provided some support for the notion that a direct modulation of the secretory apparatus could be involved. RR-evoked release was first tested in a control period, then after $3 \mathrm{~min}$ in the presence of $400 \mathrm{~nm} \mathrm{CPA}$, and then again after a 5 min washout of CPA. We found that RR-evoked release was strongly attenuated by CPA (Fig. $8 A$ ). The effect was reversible upon washout of CPA (Fig. $8 B$ ). RR-evoked release was decreased by CPA in eight of eight experiments; on average, it was $34.1 \pm 6.2 \%$ of that measured in normal saline, whereas after washout of CPA, RRevoked release recovered to $79.6 \pm 17.3 \%$ of that in normal saline (significantly different from the CPA period; $p<0.02$; paired $t$ test). By comparison, spontaneous mEPSC frequency in the presence of CPA was $81.3 \pm 13.4 \%$ of that in normal saline $(n=10$; $p<0.05$; paired $t$ test). These results provide the most compelling evidence to date for the hypothesis that activation of presynaptic $A_{1}$ adenosine receptors induces a direct modulation of the effectiveness of the secretory machinery in hippocampal neurons.

\section{DISCUSSION}

\section{Modulation of secretion}

The recent characterization of numerous synaptic proteins has raised the possibility of eventually pinpointing some of these proteins as targets for regulation during development of the synapse and its modulation in the context of learning and memory or pathology (Jahn and Südhof, 1994; O'Connor et al., 1994; Scheller, 1995). Toward this end, it is clear that tools must be developed to directly probe the release machinery of neurons in order to identify changes in the efficacy of the processes that are downstream from calcium influx through voltage-dependent channels. To date, it has proven difficult to identify a method to reversibly induce quantal release in neurons in a calcium-independent manner. 
A

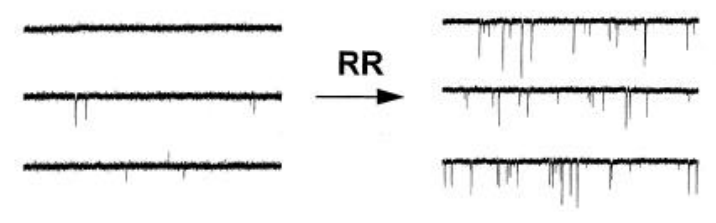

N.S.

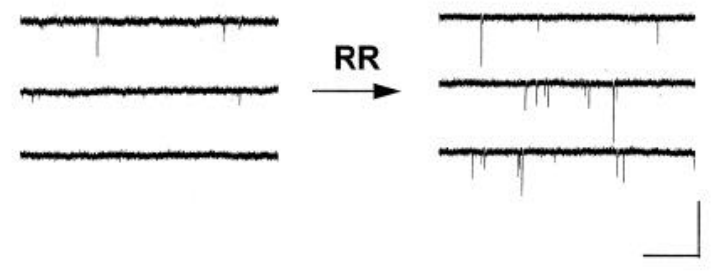

CPA

B

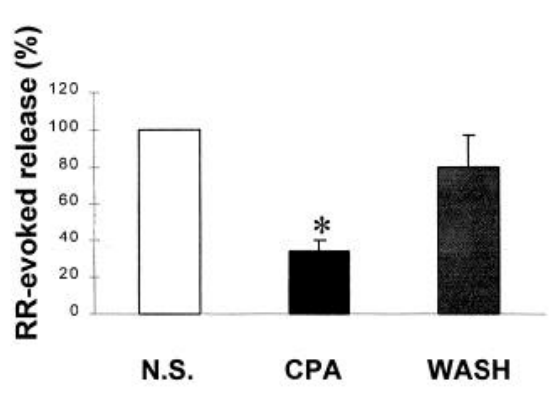

Figure 8. Direct modulation of the secretory apparatus by $\mathrm{A}_{1}$ adenosine receptor activation. $A, \mathrm{RR}$-induced increase in mEPSC frequency in normal saline (N.S.) and again in the same neuron after perfusion of 400 nM cyclopentyladenosine (CPA). The RR-evoked release is significantly decreased. Calibration: $80 \mathrm{pA}, 675 \mathrm{msec}$. $B$, Summary of experiments performed with CPA. RR-evoked release was evaluated three times in each neuron: during a control period in normal saline (N.S.), 3 min from the start of CPA (400 nM) perfusion, and finally again in normal saline after a 5 min washout of CPA $(W A S H)$. The effects are expressed relative to the RR-evoked release obtained during the initial control trial. The bars represent the mean \pm SEM of eight experiments. Note that the decrease in RR-evoked release was reversible upon washout of CPA. " $p<0.05$

The work presented here suggests that RR could be used in such a way. Four lines of evidence suggest that its induction of secretion in cultured hippocampal neurons is calcium-independent. First, its effect is not prevented by removal of external calcium (Fig. 3A,B). Second, RR by itself blocks calcium channels (Fig. $3 C$ ). Third, perturbation of intracellular calcium stores neither induces large changes in spontaneous release by itself nor prevents the effects of RR (Fig. 4A,B). Fourth, direct measurements of free calcium levels in neurites and cell bodies of hippocampal neurons failed to detect any change in the presence of RR (Fig. 5).

We have provided an initial demonstration of the usefulness of $\mathrm{RR}$ as a probe of the release machinery of neurons by showing that it could identify an $A_{1}$ adenosine receptor-mediated decrease of the efficacy of the release process in hippocampal neurons (Fig. 8). Such a possibility had been suggested previously based on measurements of rates of spontaneous release alone (Scanziani et al., 1992; Scholz and Miller, 1992). We find RR-evoked release to be a much more sensitive assay to detect modulation of the secretory machinery. Although the decrease in spontaneous release was found to be less than $20 \%$, RR-evoked release decreased by $65 \%$ (Fig. $8 B$ ). It will be interesting to use RR-evoked release as an assay for presynaptic changes in the context of long-term potentiation (LTP) of synaptic transmission. Our data may allow an immediate reinterpretation of the findings of Lynch and Bliss (1986), who reported that RR-evoked release of labeled glutamate is increased in slices in which LTP has been induced. These authors had used RR as a stimulus for release under the assumption that its effects were mediated by the release of calcium from mitochondrial stores. We now suggest that their results may be interpreted as indicating that LTP is indeed accompanied by a direct upregulation of the effectiveness of the release machinery in hippocampal neurons.

\section{Mechanism of action of RR}

Our results are compatible with a model of RR action on synaptic terminals that involves direct binding to the presynaptic membrane with a subsequent, calcium-independent induction of quantal transmitter release. Several observations support the proposition that an external site of action is involved. First, the kinetics of action are fast; the increase in mEPSC frequency begins immediately upon puff application of RR (Fig. 1B). Second, the effect is reversed relatively rapidly by washing with saline (Fig. $1 C$ ). Third, increasing external $\mathrm{Ca}^{2+}$ decreases the effectiveness of RR (Fig. $3 B$ ). Fourth, puff application of heparin is able to rapidly reverse the sustained increase in mEPSC frequency induced by prolonged application of RR (Fig. 6). Finally, it has been independently determined that polycationic molecules such as RR and lanthanum are usually impermeant to the intact cellular membrane (Tani and Ametani, 1971; Korte and Rosenbluth, 1982; Humbert and Pévet, 1992).

RR is likely to bind to multiple categories of binding sites on neurons and cells in general. Three of these are (1) polyanionic carbohydrates such as $\mathrm{N}$-linked oligosaccharides on glycoproteins, ganglioside headgroups, and proteoglycans containing sulfated sugars and uronic acid; (2) amino acid residues of proteins; and (3) membrane lipids. What then is the class of binding sites responsible for the induction of secretion? It may be proposed that the induction of secretion is secondary to the binding of RR to the carbohydrate moieties of glycoproteins present at the synapse. This could result in the aggregation of some proteins such as receptors with tyrosine kinase function (Lemmon and Schlessinger, 1994) and could initiate a second-messenger cascade leading to neurotransmitter release in a way reminiscent of the induction of histamine release from mast cells by aggregation of Fc epsilon receptors (Beaven and Metzger, 1993). Although at this point we cannot eliminate such a possibility, the fast kinetics of RR action on mEPSCs and the fast reversal of its effects by heparin are not suggestive of any involvement of complex secondmessenger pathways. A second possibility is direct binding to proteins. One example of this is the block of $\mathrm{Ca}^{2+}$ channels by RR (Fig. 3), which is likely to result from binding of RR to sites at the mouth of the channel that normally allows binding and permeation of $\mathrm{Ca}^{2+}$ ions. One possibility could be that this binding of $\mathrm{RR}$ also induces a conformational change in the channel such that proteins of the presynaptic membrane and vesicle that normally interact with calcium channels, like the neurexins and synaptotagmin, also are influenced, thereby directly facilitating exocytosis. A third possibility is direct binding of RR to membrane lipids. Work performed with purified lipids and liposomes has demonstrated previously that polyvalent cations like RR and lanthanum are able to bind strongly and be coordinated by phospholipids (Luft, 1971; Cullis et al., 1980; Petersheim and Sun, 1989; Ohki and Arnold, 1990). This could force nonlamellar states in the membrane (Sun 
and Petersheim, 1990). The induction of inverted micelle structures, hexagonal phases, or other intermediate states in phospholipid membranes by $\mathrm{Ca}^{2+}$ and other di- and multivalent cations is well documented and could be a necessary step in exocytosis (Papahadjopoulos et al., 1976; Cullis et al., 1980; Allen et al., 1990; Benfenati et al., 1993; Rand and Fang, 1993; Scheller, 1995). More simple molecular packing "mismatches" also could be induced in phospholipid bilayers and could facilitate fusion (Burgess et al., 1992). The induction of such nonlamellar states in the presynaptic membrane after the binding of RR could directly decrease the energy barrier for exocytosis of predocked vesicles, for example, by making it easier for the protein complex that mediates neurotransmitter release in neurons to overcome the repulsive forces provided by the hydration layers of the presynaptic membrane and vesicle surface (Bass and Moore, 1966; Remler, 1973). However, to be compatible with the results presented in this paper, such alterations in bilayer organization must be reversible.

Although identification of the precise mechanism by which RR induces calcium-independent secretion will require more work, we suggest that RR may be an extremely useful tool for the study of the process of neurotransmitter release and its modulation in neurons because it provides a dircct assay of the statc of the secretory apparatus. In particular, the use of RR as a calciumindependent stimulus for secretion may allow a more direct investigation of questions such as the relationship between the mechanism of calcium-dependent versus calcium-independent exocytosis, and the role of calcium influx in endocytosis.

\section{REFERENCES}

Allen TM, Kong K, Papahadjopoulos D (1990) Membrane contact, fusion, and hexagonal $\left(\mathrm{H}_{\mathrm{II}}\right)$ transitions in phosphatidylethanolamine liposomes. Biochemistry 29:2976-2985.

Alnaes E, Rahamimoff R (1975) On the role of mitochondria in transmitter release from motor nerve terminals. J Physiol (Lond) 248:285-306.

Argov Z, Yaari Y (1979) The action of chlorpromazine at an isolated cholinergic synapse. Brain Res 164:227-236.

Baker PF, Crawford AC (1975) A note on the mechanism by which inhibitors of the sodium pump accelerate spontaneous release of transmitter from motor nerve terminals. J Physiol (Lond) 247:209-226.

Basarsky TA, Parpura V, Haydon PG (1994) Hippocampal synaptogenesis in cell culture: developmental time course of synapse formation, calcium entry, and synaptic protein distribution. $J$ Neurosci 14:6402-6411.

Bass L, Moore WJ (1966) Electrokinetic mechanism of miniature postsynaplic potentials. Proc Natl Acad Sci USA 55:1214-1217.

Beaven MA, Metzger H (1993) Signal transduction by Fc receptors: the Fc epsilon RI case. Immunol Today 14:222-226.

Benfenati F, Valtorta F, Rossi MC, Onofri F, Sihra T, Greengard $P$ (1993) Interactions of synapsin I with phospholipids: possible role in synaptic vesicle clustering and in the maintenance of bilayer structures. J Cell Biol 123:1845-1855.

Broekemeier KM, Krebsbach RJ, Pfeiffer DR (1994) Inhibition of the mitochondrial $\mathrm{Ca}^{2+}$ uniporter by pure and impure ruthenium red. Mol Cell Biochem 139:33-40.

Brosius DC, Hackett JT, Tuttle JB (1992) $\mathrm{Ca}^{2+}$-independent and $\mathrm{Ca}^{2+}$ dependent stimulation of quantal neurosecretion in avian ciliary ganglion neurons. J Neurophysiol 68:1229-1234.

Burgess SW, McIntosh TJ, Lentz BR (1992) Modulation of poly(ethylene glycol)-induced fusion by membrane hydration: importance of interbilayer separation. Biochemistry 31:2653-2661.

Cullis PR, DeKruijff B, Hope MJ, Nayar R, Schmid SL (1980) Phospholipids and membrane transport. Can J Biochem 58:1091-1100.

Delaney KR, Zucker RS (1990) Calcium released by photolysis of DMnitrophen stimulates transmitter release at squid giant synapse. J Physiol (Lond) 426:473-498.
Delaney KR, Tank DW, Zucker RS (1991) Presynaptic calcium and serotonin-mediated enhancement of transmitter release at crayfish neuromuscular junction. J Neurosci 11:2631-2643.

Gage PW (1965) The effect of methyl, ethyl and n-propyl alcohol on neuromuscular transmission in the rat. J Pharmacol Exp Ther 150:236-243.

Gomis A, Gutierrez LM, Sala F, Viniegra S, Reig JA (1994) Ruthenium red inhibits selectively chromaffin cell calcium channels. Biochem Pharmacol 47:225-231.

Grubb BD, Harris JB, Schofield IS (1991) Neuromuscular transmission at newly formed neuromuscular junctions in the regenerating soleus muscle of the rat. J Physiol (Lond) 441:405-421.

Haimann C, Torri-tarelli F, Fesce R, Ccccarelli B (1985) Mcasurement of quantal secretion induced by ouabain and its correlation with depletion of synaptic vesicles. J Cell Biol 101:1953-1965.

Heuser J, Miledi R (1971) Effects of lanthanum ions on function and structure of frog neuromuscular junctions. Proc R Soc Lond [Biol] 179:247-260.

Humbert W, Pévet P (1992) Permeability of the pineal gland of the rat to lanthanum: significance of dark pinealocytes. $J$ Pineal Res 12:84-88.

Jahn R, Südhof TC (1994) Synaptic vesicles and exocytosis. Annu Rev Neurosci 17:219-246.

Klein M (1994) Synaptic augmentation by 5-HT at rested Aplysia sensorimotor synapses: independence of action potential prolongation. Neuron 13:159-166.

Korte GE, Rosenbluth J (1982) Anionic sites on the surface of frog ependymal astrocytes and mouse ependymal cells. Anat Rec 204:95-100.

Landò L, Giovanni J, Zucker RS (1986) Cobalt blocks the decrease in mEPSP frequency on depolarization in calcium-free hypertonic media. J Neurobiol 17:707-712.

Lemmon MA, Schlessinger J (1994) Regulation of signal transduction and signal diversity by receptor oligomerization. Trends Biochem Sci $19: 459-463$.

Luft JH (1971) Ruthenium red and violet. I. chemistry, purification, methods of use for electron microscopy and mechanism of action. Anat Rec 171:347-368.

Lynch MA, Bliss TVP (1986) On the mechanism of enhanced release of $\left[{ }^{14} \mathrm{C}\right]$ glutamate in hippocampal long-term potentiation. Brain Res 369:405-408.

Malgaroli A, Ting AE, Wendland B, Bergamaschi A, Villa A, Tsien RW, Scheller RH (1995) Presynaptic component of long-term potentiation visualized at individual hippocampal synapses. Nature 268:1624-1628.

Malgaroli A, Tsien RW (1992) Glutamate-induced long-term potentiation of the frequency of miniature synaptic currents in cultured hippocampal neurons. Nature 357:134-139.

Man-Son-Hing H, Zoran MJ, Lukowiak K, Haydon PG (1989) A neuromodulator of synaptic transmission acts on the secretory apparatus as well as on ion channels. Nature 341:237-239.

Mellanby J, Beaumont MA, Thompson PA (1988) The effects of lanthanum on nerve terminals in goldfish muscle after paralysis with tetanus toxin. Neuroscience 25:1095-1106.

Mogul DJ, Adams ME, Fox AP (1993) Differential activation of adenosine receptors decreases $\mathrm{N}$-type but potentiates $\mathrm{P}$-type $\mathrm{Ca}^{2+}$ current in hippocampal CA3 neurons. Neuron 10:327-334.

Moore CL (1971) Specific inhibition of mitochondrial $\mathrm{Ca}^{2+}$ transport by ruthenium red. Biochem Biophys Res Commun 42:298-305.

Mulkey RM, Zucker RS (1993) Calcium release by photolysis of DMnitrophen triggers transmitter release at the crayfish neuromuscular junction. J Physiol (Lond) 462:243-260.

O'Connor V, Augustine GJ, Betz H (1994) Synaptic vesicle exocytosis: molecules and models. Cell 76:785-787.

Ohki S, Arnold K (1990) Surface dielectric constant, surface hydrophobicity and membrane fusion. J Membr Biol 114:195-203.

Papahadjopoulos D, Vail WJ, Pangborn WA, Poste G (1976) Studies on membrane fusion. II. induction of fusion in pure phospholipid membranes by calcium ions and other divalent metals. Biochim Biophys Acta $448: 265-283$

Parsons NJ, Curry A, Fox AJ, Jones DM, Cole JA, Smith H (1992) The serum resistance of gonococci in the majority of urethral exudates is due to sialyted lipopolysaccharide seen as a surface coat. FEMS Microbiol Lett 90:295-300.

Petersheim M, Sun J (1989) On the coordination of $\mathrm{La}^{3+}$ by phosphatidylserine. Biophys $\mathbf{J}$ 55:631-636. 
Powis DA, Clark CL, O'Brien KJ (1994) Lanthanum can be transported by the sodium-calcium cxchangc pathway and directly triggers catecholamine release from bovine chromaffin cells. Cell Calcium $16: 377-390$.

Quastel DMJ, Hackett JT, Cooke JD (1971) Calcium: is it required for transmitter release? Science 172:1034-1036.

Raastad M, Storm JF, Andersen P (1990) Elementary excitatory synaptic currents in dentate granule and hippocampal pyramidal cells. Soc Neurosci Abstr 16:674.

Rand RP, Fang Y (1993) Structures and energetics of phospholipid and diacylglycerol assemblies relative to membrane fusion. Biochem Soc Trans 21:266-270.

Remler MP (1973) A semiquantitative theory of synaptic vesicle movements. Biophys J 13:104-117.

Rosenthal L, Zacchetti D, Madeddu L, Meldolesi J (1991) Mode of action of $\alpha$-latrotoxin: role of divalent cations in $\mathrm{Ca}^{2+}$-dependent and $\mathrm{Ca}^{2+}$-independent effects mediated by the toxin. Mol Pharmacol 38:917-923.

Scanziani M, Capogna M, Gähwiler BH, Thompson SM (1992) Presynaptic inhibition of miniature excitatory synaptic currents by baclofen and adenosine in the hippocampus. Neuron 9:919-927.

Scheller RH (1995) Membrane trafficking in the presynaptic nerve terminal. Neuron 14:893-897.
Scholz KP, Miller RJ (1991) Analysis of adenosine actions on $\mathrm{Ca}^{2+}$ currents and synaptic transmission in cultured rat hippocampal neurons. J Physiol (Lond) 435:373-393.

Scholz KP, Miller RJ (1992) Inhibition of quantal transmitter release in the absence of calcium influx by a $G$ protein-linked adenosine receptor at hippocampal synapses. Neuron 8:1139-1150.

Sun I, Petersheim M (1990) I anthanide(III)-phosphatidic acid complexes: binding site heterogeneity and phase separation. Biochim Biophys Acta 1024:159-166.

Tani E, Ametani T (1971) Extracellular distribution of ruthenium redpositive substances in the cerebral cortex. J Ultrastruct Res 34:1-14.

Umemiya M, Berger AJ (1994) Activation of adenosine $A_{1}$ and $A_{2}$ receptors differentially modulates calcium channels and glycinergic synaptic transmission in rat brainstem. Neuron 13:1439-1446.

White RJ, Reynolds IJ (1995) Mitochondrial and $\mathrm{Na}^{+} / \mathrm{Ca}^{2+}$ exchange buffer glutamate-induced calcium loads in cultured cortical neurons. $J$ Neurosci 15:1318-1328.

Wu L-G, Saggau P (1994) Adenosine inhibits evoked synaptic transmission primarily by reducing presynaptic calcium influx in area CA1 of hippocampus. Neuron 12:1139-1148.

Zucker RS, Haydon PG (1988) Membrane potential has no direct role in evoking neurotransmitter release. Nature 335:360-362. 